Journal of

Women's Health and Gynecology

\title{
Emerging Role of Gynecologic Oncologist as BRCA Mutation Counselor for Breast Cancer Patients
}

\section{Min Kyu Kim*}

Department of Obstetrics and Gynecology, Samsung Changwon Hospital, Sungkyunkwan University School of Medicine, Changwon, Korea

${ }^{\star}$ Corresponding author: Min Kyu Kim, M.D., Ph. D, Department of Obstetrics and Gynecology, Samsung Changwon Hospital, Sungkyunkwan University School of Medicine, Hap sung-Dong, Masan Hoewon-Gu Changwon-si, Korea, Tel: 82-55-2335922, Fax: 82-55-233-5299, E-mail: minkyukim@skku.edu

Received Date: March 02, 2019 Accepted Date: April 11, 2019 Published Date: April 12, 2019

Citation: Min Kyu Kim (2019) Emerging Role of Gynecologic Oncologist as BRCA Mutation Counselor for Breast Cancer Patients. J Womens Health Gyn 6: 1-3.

\begin{abstract}
Background: BRCA mutations carry a lifetime risk of breast and ovarian cancer. Although breast cancer occurs more frequently than ovarian cancer, it has lower mortality in Korea and the United states. Providing genetic counseling for BRCA mutation carriers provides several advantages in the prevention and treatment of both cancers. The objective of this study was to investigate the role of gynecologic oncologists as genetic counselors for BRCA mutation in breast cancer.

Material \& Methods: We performed a retrospective review of patients diagnosed with breast cancer who had visited a gynecologic oncology clinic for a variety of reasons. Clinical information of age, family and personal history of cancer, and purpose of clinic visit was extracted from their medical records. Genetic counseling of BRCA1 and 2 mutations was offered to any patient who had not undergone counseling previously. Risk management and further counseling were offered to inform patients about risk-reducing surgery and cascade testing of family members after obtaining results of such mutations.

Outcomes: A total of 33 breast cancer patients who had visited a gynecologic clinic were selected. The most common purpose of visit was routine gynecological exam (16/33) and the second most common was gynecologic problems with fibroids, ovarian cysts, and vaginal spotting (15/33). Two patients visited for risk-reducing surgery consultation. Median ages at clinic visit and diagnosis of breast cancer were 46 (range, 32-69) and 44 (range, 32-69) years, respectively. Fourteen $(14 / 33,42 \%)$ patients were stage IA and three patients were triple negative (ER/PR/HER2/neu). Eighteen (18/33, 55\%) patients were taking tamoxifen. Five patients had a family history of BRCA-related cancer. Among 33 patients, only three with BRCA results had BRCA counseling by a breast cancer surgeon and $11(11 / 33,37 \%)$ patients accepted BRCA gene testing. Two patients had BRCA1 germline mutations and two had BRCA2 mutations. Three patients had VUS (Variation of Unknown Mutation). Information about risk-reducing surgery and family counseling were provided for all patients who were positive for mutation.
\end{abstract}

Conclusions: Genetic counseling about BRCA mutations in breast cancer patient by experienced gynecologic oncologists is feasible. Breast cancer patients with gynecologic issues are encouraged to receive genetic counseling by gynecologic oncologists.

Keywords: BRCA mutation; Breast cancer; Genetic counseling

(02019 The Authors. Published by the JScholar under the terms of the Creative Commons Attribution License http://creativecommons.org/licenses/ by/3.0/, which permits unrestricted use, provided the original author and source are credited. 


\section{Introduction}

Breast cancer is the most prevalent type of cancer among women worldwide, representing 266,120/19,219 of new cases and 40,920/2,354 of deaths in the USA/ South Korea. Ovarian carcinoma represents the seventh leading cancer among women in the USA/South Korea. An estimated 22,240/2,443 new cases of ovarian carcinomas will be diagnosed and approximately 14,070/1,055 ovarian carcinoma-related deaths are expected $[1,2]$.

Gynecologic and gynecologic oncology clinic visits and consultations related to breast cancer diagnosis and treatment are performed for many reasons, including common gynecologic problems presenting with dysmenorrhea, menstrual irregularity with or without uterine myoma, adnexal masses, infertility, menopausal symptoms, bone loss related to use of $\mathrm{GnRH}$ agonist, and endometrial cancer risk evaluation associated with tamoxifen use [3-8]. BRCA mutation patients have a lifetime risk of breast and ovary cancer. Physicians have a responsibility and duty to treat them. BRCA1 and BRCA2 germline mutations account for the majority of hereditary ovarian carcinoma. Affected patients should receive appropriate counseling [9]. Knowing BRCA mutation status in breast cancer patients has several advantages, including therapeutic gain, secondary cancer risk evaluation, and prevention [10,11]. Determining the proportion and characteristics of women who have BRCA1 and BRCA2 genes is important because it enables appropriate provision of genetic counseling and testing to those women and their family members as part of medical management [12]. There are many barriers to obtain increased rate of BRCA testing among breast cancer patients. These barriers include psychological stress, cost, physician awareness, counseling information timing, and provider position [13-17]. Referral and counseling can be easily missed for those with BRCA mutations in ovarian cancer [18]. The same is true for BRCA mutations in ovarian cancer patients seeking medical attention for breast problems. Physicians can be counselors for these patients and their family members. Further, new technology for gene sequencing has made it easier to perform screening using multiple gene panels [19]. Studies that determine the impact of genetic risk evaluation about BRCA mutations among breast cancer patients who visit gynecologic clinics are insufficient. Therefore, the objective of this study was to investigate the role of gynecologic oncologists as genetic counselors for BRCA mutation in breast cancer.

\section{Material \& Methods}

We identified a total of 33 breast cancer patients who had visited a gynecologic oncology clinic for various reasons. We offered genetic counseling for hereditary breast and ovarian cancer. The counseling included risk assessment based on pathology, a concrete family history, education about genetics of hereditary breast and ovarian cancer, genetic testing methods, cost and meaning of the results, benefits and risks of genetic testing, and importance of sharing testing results with family members. After receiving informed consent, BRCA1/2 gene sequencing was done for approved patients. Among BRCA-positive and Variation of Unknown Mutation (VUS) patients, a second genetic counseling session for risk management options was performed (family counseling, risk reducing surgery, surveillance for BRCA-associated cancer, and chemoprevention). Clinical information such as age, family and personal history of cancer including ovarian and breast cancer, stage at diagnosis, and histology type was extracted from their medical records. Data were analyzed using SPSS software version 12.0 (SPSS, Inc., Chicago, IL, USA) and R 3.1.0 (Vienna, Austria; http://www.R-project.org/). Comparison of means of variables was performed using Fisher's exact test, Independent t-test, and Mann-Whitney test. A P value $<0.05$ was considered statistically significant.

\section{Genetic counseling}

Genetic counseling was offered twice. At the first visit, pretest education including information about hereditary ovarian carcinoma, complete family history, and cost was provided. The second counseling included posttest education about gene sequencing results. There were three groups requiring counseling, the positive group (germline mutation), cascade testing of family members, and management education about risk-reducing surgery. For VUS, no treatment was scheduled. However, in silico analysis and cascade testing were provided. For mutation-negative patients with a strong family history, a gene panel test (except BRCA1 and 2) was suggested.

\section{Sequencing process}

Blood samples were collected from patients after obtaining informed consent. Genomic DNA was isolated from peripheral blood leukocytes using Wizard Genomic DNA Purification Kit (Promega, WI, USA) according to the manufacturer's instructions. All coding exons and flanking introns of target genes (BRCA1 and BRCA2) were amplified by polymerase chain reaction on a Thermal Cycler 9700 (Applied Biosystems, Foster City, CA, USA) with primers designed by the authors. Five microliters of PCR amplification products were treated with $2 \mathrm{U}$ shrimp alkaline phosphatase and $10 \mathrm{U}$ exonuclease 1 (USB Corporation, Cleveland, OH, USA). Direct sequencing was performed using Big Dye Terminator Cycle Sequencing Ready Reaction Kit on an ABI Prism 3130 Genetic Analyzer (Applied Biosystems). Sequences were analyzed using the Sequencer program (Gene Codes Corporation, Ann Arbor, MI, USA) and were compared to reference sequences. Sequence variations were described according to the recommendations of the Human Genome Variation Society (http://www.hgvs. org/mutnomen/).

\section{Results}

Procedures were offered to patients as shown in Figure 1 according to patient approval and request. The median age of breast cancer diagnosis was 44 years (range, 32 to 69 years) and the median age for visiting a gynecologic clinic and 
undergoing BRCA testing was 46 years (range, 35 to 70 years). The frequency of family history of cancer was 36\% (12/33). Patients were equally divided between BRCA-related and nonBRCA-related cancer history. Fourteen (14/33, 42\%) patients were stage IA and three patients were triple negative (ER/PR/ HER2/neu). About half (19/33, 58\%) of these patients received chemotherapy. Tamoxifen treatment was prescribed in about $50 \%(18 / 33,55 \%)$ of patients. Eighteen percent of patients received $\mathrm{GnRH}$ agonist (Table 1). The main primary purpose of visit for our patient cohort was routine gynecological exam $(16 / 33,48 \%)$. The second most common reason was gynecologic problems with pelvic mass like uterine myoma and adnexa mass $(11 / 33,33 \%)$. Two patients visited for riskreducing surgery consultation based on family history or age without knowledge of BRCA mutation. Four of 33 patients were seeking consultation for menopausal symptoms and bone loss problems (12\%) (Table 2). Three patients received or had heard about genetic mutation risk through their breast cancer surgeon. However, most (30/33 91\%) patients had not received any education before the gynecologic clinic visit. The number of consultation requests and referrals from breast cancer surgeons was 10 (10/33, $30 \%)$. Most (23/33, 70\%) patients had not received a referral. The amount of counseling received was 35.63 minutes (range, 30 to 60 minutes). After education, $11(11 / 30,37 \%)$ patients accepted BRCA gene testing. Among 33 patients, only 3 had BRCA counseling, resulting in breast cancer surgery (Table 3). Two BRCA1 germline mutation patients and two BRCA2 mutation patients were found. There were 3 VUS patients. Risk-reducing surgery and family counseling were suggested for patients who were positive for mutation (Table 4).

\begin{tabular}{|l|l|}
\hline variables & No(percents) \\
\hline Routine check & $16(48 \%)$ \\
\hline Gy poroblem & $11(33 \%)$ \\
\hline Ovary cys. tumor & 5 \\
\hline Myoma & 6 \\
\hline GnRH against, Menopause Sx & $4(12 \%)$ \\
\hline Risk reducing surgery(RRS) & $2(6 \%)$ \\
\hline
\end{tabular}

Table 1. Patient characteristics

\begin{tabular}{|l|l|}
\hline Variables & No(percents) \\
\hline $\begin{array}{l}\text { Genetic education experience before } \\
\text { GY clinic visit }\end{array}$ & \\
\hline Yes & $3(9 \%)$ \\
\hline No & $30(91 \%)$ \\
\hline Physician referral for GY clinic visit & \\
\hline Yes & $10(30 \%)$ \\
\hline No & $23(70 \%)$ \\
\hline Counseling time. min & $32.63(30-60)$ \\
\hline Gene test approval rate & $11 / 30(37 \%)$ \\
\hline
\end{tabular}

Table 2. Reasons for clinic visit

\begin{tabular}{|l|l|}
\hline Variables & No (percents) \\
\hline BRCA1 Germline mutation & 2 \\
\hline BRCA2 Germline mutation & 2 \\
\hline VUS & 3 \\
\hline Negative & 4 \\
\hline
\end{tabular}

Table 3. Genetic counseling education and approval

\begin{tabular}{|l|l|}
\hline Variables & Breast ca $(\mathrm{n}=33)$ \\
\hline Age at diagnosis, years & $44(32-69)$ \\
\hline Age at GY clinic visit & $46(35-70)$ \\
\hline Family history ${ }^{\star}$ & $12^{\star}(36 \%)$ \\
\hline BRCA related & $6(18 \%)$ \\
\hline BRCA non related & $6(18 \%)$ \\
\hline Stage & \\
\hline Stage I & $14(42 \%)$ \\
\hline Stage II & $11(33 \%)$ \\
\hline Stage III & $3(9 \%)$ \\
\hline Unknown & $5(9 \%)$ \\
\hline ER/PR/HER2(/-/-) & $3(9 \%)$ \\
\hline Adjuvant Tx & \\
\hline Chemotherapy & $19(58 \%)$ \\
\hline Radiation & $21(64 \%)$ \\
\hline Tamoxifen Tx & $18(55 \%)$ \\
\hline GnRH against & $6(18 \%)$ \\
\hline
\end{tabular}

Table 4. Test \& counseling results

*:BRCA-related: Breast, Ovary, Pancreas, Prostate Cancer

\section{Discussion}

This study emphasizes the role of gynecologic oncologists as genetic counselor in providing genetic counseling information and test result education for breast cancer patients. BRCA mutation test accessibility has risen over the last few years with advances of technology. There are many breast surgeons providing genetic counseling and testing services [20]. However, there are several barriers that prevent patients from obtaining BRCA testing, including mental stress, cost of test, physician awareness, counseling timing, and provider attitude [13-17].

The frequency of germline BRCA mutation is around $15 \%$ in triple-negative breast cancer registry [21]. In our study, there were $3(9 \%, 3 / 33)$ triple-negative patients. Of these, one patient had a BRCA 2 mutation with a sister having breast cancer. Thus, she underwent risk-reducing bilateral salpingooophorectomy.

There are several advantages for gynecologic physicians to have knowledge of BRCA mutation status among 


\section{Breast cancer Dx \& Tx}

\section{GY clinic visit}

\section{Sx management, Routine GY screening}

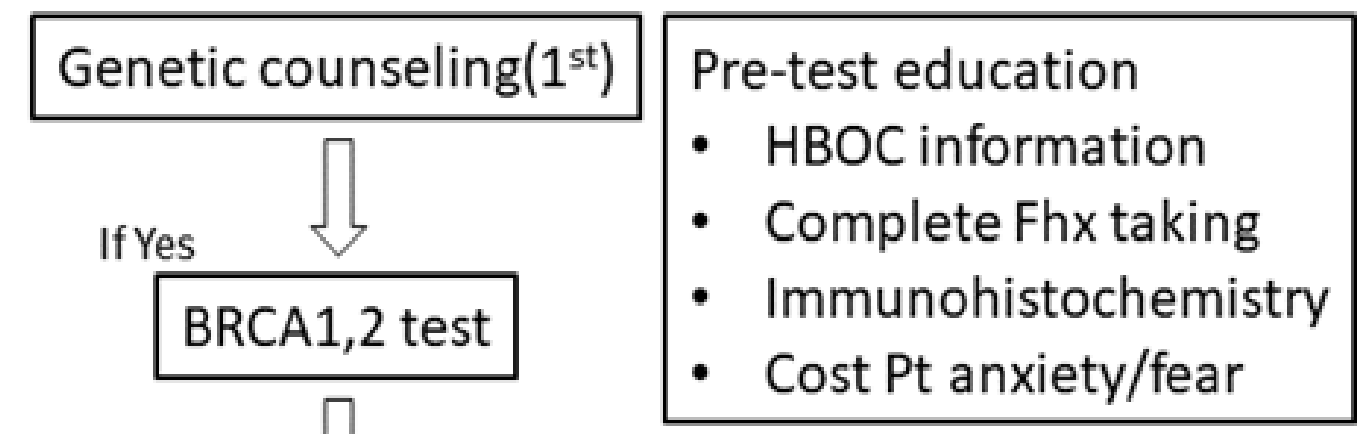

After result Genetic counseling( $\left.2^{\text {st }}\right)$

\section{Pre-test education \\ - Positive(Germline mutation)- cascade testing \\ - VUS(variation of unknown significance) \\ - Negative with strong family history}

Figure.1: Genetic counseling procedure

breast cancer patients. The mutation status can inform them on whether they should operate on suspicious adnexal masses [8]. Breast cancer patients are at high risk for uterine myoma [3]. In our study, we found 5 adnexal masses and 6 uterine myoma patients. Although they were not associated with germline BRCA mutations, these might be opportunities for gynecologist counseling. Recent studies do not recommend routine endometrial surveillance for asymptomatic breast cancer patients on tamoxifen, even though they are at increased risk for endometrial cancer [5]. This adds another reason to visit a gynecologic oncologic clinic. In the present study, 18 $(18 / 33,55 \%)$ patients were taking tamoxifen. BRCA mutation has been reported to be associated with endometrial cancer in some types [22].

Several menopausal symptoms are issues for breast cancer patients, including bone loss problems [23]. Several non-pharmacologic therapies including acupuncture and cognitive behavioral therapy have been suggested instead of hormonal agents [24]. Specific considerations regarding bone loss associated with premature menopause among breast cancer patients have been proposed [25], providing additional motivation for a clinic visit.

A recent report in Korea has shown that implementation of national health insurance coverage (18 August 2005) for BRCA1/2 genetic testing has reduced refusal rate [26] due to reduced cost barrier for ovarian and breast cancer patients. Our study had several limitations. Specialized genetic counselors are considered more suitable for providing genetic counseling and test information while audio and visual information may replace some roles of health care providers $[15,17]$. Further, the number of breast cancer patients is much greater than that of ovarian cancer patients. BRCA testing is easily skipped by surgeons. The indication for insurance coverage is not as broad as that for ovarian cancer patients. Diagnostics between these two cancers also vary as ovaries are internal and breasts are external. Consultation and cooperation between breast surgeon and gynecologic department is 
necessary to ensure optimal management of treatment.

In summary, genetic counseling about BRCA mutations in breast cancer patients by an experienced gynecologic oncologist is feasible. Breast cancer patients with gynecologic issues are encouraged to obtain genetic counseling from gynecologic oncologists.

\section{References}

1. Torre LA, Trabert B, DeSantis CE. (2018) Ovarian cancer statistics. CA Cancer J Clin. 4:284-296.

2. Jung KW, Won YJ, Kong HJ, Lee ES. (2018) Community of Population-Based Regional Cancer R. Cancer Statistics in Korea: Incidence, Mortality, Survival, and Prevalence in 2015. Cancer Res Treat. 2:303-316.

3. Tseng JJ, Chen YH, Chiang HY, Lin CH. (2017) Increased risk of breast cancer in women with uterine myoma: a nationwide, population-based, case-control study. J Gynecol Oncol. 3: e35.

4. Hanson B, Johnstone E, Dorais J, Silver B, Peterson CM, Hotaling J. (2017) Female infertility, infertility-associated diagnoses, and comorbidities: a review. J Assist Reprod Genet. 2:167-177.

5. Fleming CA, Heneghan HM, O'Brien D, McCartan DP, McDermott EW, Prichard RS. (2018) Meta-analysis of the cumulative risk of endometrial malignancy and systematic review of endometrial surveillance in extended tamoxifen therapy. Br J Surg.

6. Rachner TD, Coleman R, Hadji P, Hofbauer LC. (2018) Bone health during endocrine therapy for cancer. Lancet Diabetes Endocrinol.

7. Leon-Ferre RA, Majithia N, Loprinzi CL. (2017) Management of hot flashes in women with breast cancer receiving ovarian function suppression. Cancer Treat Rev. 52:82-90.

8. Reinert T, Nogueira-Rodrigues A, Kestelman FP, AshtonProlla P, Graudenz MS, Bines J. (2018) The Challenge of Evaluating Adnexal Masses in Patients with Breast Cancer. Clin Breast Cancer. 4: e587-e594.

9. Pal T, Vadaparampil ST. (2012) Genetic risk assessments in individuals at high risk for inherited breast cancer in the breast oncology care setting. Cancer Control. 4:255-266.

10. Le D, Gelmon KA. (2018) Olaparib tablets for the treatment of germ line BRCA-mutated metastatic breast cancer. Expert Rev Clin Pharmacol. 9:833-839.

11. Kushner CJ, Hwang WT, Wang S, Solin LJ, Vapiwala N. (2018) Long-term risk of second malignancies in women after breast conservation therapy for ductal carcinoma in situ or early-stage breast cancer. Breast Cancer Res Treat. 1:45-53.
12. Roukos DH, Briasoulis E. (2007) Individualized preventive and therapeutic management of hereditary breast ovarian cancer syndrome. Nat Clin Pract Oncol. 10:578-590.

13. Schlich-Bakker KJ, ten Kroode HF, Ausems MG. (2006) A literature review of the psychological impact of genetic testing on breast cancer patients. Patient Educ Couns. 1:13-20.

14. Tuffaha HW, Mitchell A, Ward RL, et al. (2018) Costeffectiveness analysis of germ-line BRCA testing in women with breast cancer and cascade testing in family members of mutation carriers. Genet Med.

15. Sie AS, van Zelst-Stams WA, Spruijt L. (2014) More breast cancer patients prefer BRCA-mutation testing without prior face-to-face genetic counseling. Fam Cancer. 2:143-151.

16. Wevers MR, Hahn DE, Verhoef S. (2012) Breast cancer genetic counseling after diagnosis but before treatment: a pilot study on treatment consequences and psychological impact. Patient Educ Couns. 1:89-95.

17. Fournier DM, Bazzell AF, Dains JE. (2018) Comparing Outcomes of Genetic Counseling Options in Breast and Ovarian Cancer: An Integrative Review. Oncol Nurs Forum. 1:96-105.

18. Hoskins PJ, Gotlieb WH. (2017) Missed therapeutic and prevention opportunities in women with BRCA-mutated epithelial ovarian cancer and their families due to low referral rates for genetic counseling and BRCA testing: A review of the literature. CA Cancer J Clin. 6:493-506.

19. Graffeo R, Livraghi L, Pagani O, Goldhirsch A, Partridge AH, Garber JE. (2016) Time to incorporate germline multigene panel testing into breast and ovarian cancer patient care. Breast Cancer Res Treat. 3:393-410.

20. Beitsch PD, Whitworth PW. (2014) Can breast surgeons provide breast cancer genetic testing? An American Society of Breast Surgeons survey. Ann Surg Oncol. 13:4104-4108.

21. Sharma P, Klemp JR, Kimler BF. (2014) Germline BRCA mutation evaluation in a prospective triple-negative breast cancer registry: implications for hereditary breast and/or ovarian cancer syndrome testing. Breast Cancer Res Treat. 3:707-714.

22. Biron-Shental T, Drucker L, Altaras M, Bernheim J, Fishman A. (2006) High incidence of BRCA1-2 germline mutations, previous breast cancer and familial cancer history in Jewish patients with uterine serous papillary carcinoma. Eur J Surg Oncol. 10:1097-1100.

23. Santen RJ, Stuenkel CA, Davis SR, Pinkerton JV, Gompel A, Lumsden MA. (2017) Managing Menopausal Symptoms and Associated Clinical Issues in Breast Cancer Survivors. J Clin Endocrinol Metab. 10:3647-3661. 
24. Tao WW, Tao XM, Song CL. (2017) Effects of nonpharmacological supportive care for hot flushes in breast cancer: meta-analysis. Support Care Cancer. 7:2335-2347.

25. Reid DM, Doughty J, Eastell R. (2008) Guidance for the management of breast cancer treatment-induced bone loss: a consensus position statement from a UK Expert Group. Cancer Treat Rev. 1: S3-18.

26. Sun Y, Kang E, Baek H. (2015) Participation of Korean families at high risk for hereditary breast and ovarian cancer in BRCA1/2 genetic testing. Jpn J Clin Oncol. 6:527-532.

Submit your manuscript to a JScholar journal and benefit from:

ฯ Convenient online submission

ฯ Rigorous peer review

- Immediate publication on acceptance

ๆ Open access: articles freely available online

9 High visibility within the field

- Better discount for your subsequent articles

Submit your manuscript at

http://www.jscholaronline.org/submit-manuscript.php 